these welcome strategy initiatives have to outlast the present secretary of state and the present government. They need to be endorsed and supported not only by professional groups, voluntary bodies, and public opinion but also by all the relevant government departments within Whitehall, some of which can make major decisions helping or harming the public health without it being in their remit to take it into account. Such decisions need to be coordinated at Cabinet level, as has been done in other countries and as was recommended first in the Canterbury report, ${ }^{14}$ and subsequently by the National Forum for Coronary Heart Disease Prevention on several occasions."

Other problems with the strategy relate to the different components of the United Kingdom and the degree to which decision making is delegated downwards to health regions and districts and upwards to the European Community. A health strategy and targets for England alone are complicated by the historical amalgamation of health statistics with Wales. Wales, Scotland, and Northern Ireland have a degree of autonomy in their health strategies. Because England is central and makes up the bulk of the United Kingdom it is difficult for the other three territories to operate entirely independently. Perhaps the recent appointment of the Scottish chief medical officer to the English post will help coordination

By the year 2000 the health strategies for different European states will need to be better coordinated and they will need consistently high standards of health monitoring to assess the impact of their single market policies on diverse populations. In the 1970s the European Commission seemed to be ignoring health and subsidising not only tobacco but almost all the agricultural products containing saturated fat. In the past few years some health initiatives from Brussels (which continues to subsidise tobacco production) have produced ambivalent or negative reactions from London, sometimes for doctrinaire reasons concerned with who decides. It is to be hoped that health promotion initiatives in England in the future will not be delayed just because other Europeans are enthusiastic.

\section{Conclusion}

Coronary heart disease is a major health problem that demands a powerful response. The target for reducing mortality from premature coronary heart disease by the year 2000 should be $50 \%$ and not $30 \%$. Monitoring of morbidity should be instituted and appropriate targets developed. Monitoring of risk factors in England has been inadequate and was rightly criticised by the public accounts committee. ${ }^{16} \mathrm{i}^{\mathrm{T}}$ Current proposals for monitoring in England are welcome but inadequate to report what is happening to regional and social subgroups in an increasingly heterogeneous population. The establishment of strong national smoking and nutrition policies should be an urgent priority.

Tabulations of mortality for different countries from the 1950s were provided by WHO Geneva. The views expressed here are those of the author and not those of any funding body.

1 Secretary of State for Health. The health of the nation. London: HMSO, 1991. (Cm 1523.)

2 Health Education Authority. Health update 1: coronary heart disease. London HEA, 1990.

3 World Health Organisation European Collaborative Group. Multifactorial rial in the prevention of coronary heart disease. 3 . Incidence and mortality results. Eur Heart f 1983:4:141-7.

4 World Health (Organisation. World health statistics annual 1990. Geneva: WHO, 1990)

5 WHO MONICA Project Principal Investigators (prepared by Tunstall-Pedoe H). The World Health Organisation MONICA project (monitoring trends and determinants in cardiovascular disease): a major international collaand determinants in cardovascular diset
boration. F Clin Kidemiol 1988;41:105-14.

6 Panel on Dietary Reference Values of the Committee on Medical Aspects of Food Policy. Report. Dietary reference values for food energy and nutrients for the United Kingdom. London: HMSO, 1991. (Department of Health report the United Kingdom. London: H

7 WHO MONICA Project. A worldwide monitoring system for cardiovascular diseases. World Health Statistics Annual 1989. Geneva: WHO, 1989.

8 Tunstall-Pedoe H, Smith WCS, Tavendale R. How-often-that-high graphs of serum cholesterol. Findings from the Scottish Heart Health and Scottish MONICA studies. Lancet 1989; i:540-2

9 Thelle DS, Shaper AG, Whitehead TP, Bullock DG, Ashby D. Blood lipids in middle-aged British men. Br Heart f 1983;49:205-13.

10 Gregory J, Foster $K$, Tyler $H$, Wiseman $M$. The dietary and nutritional surve of adults. London: Office of Population Censuses and Surveys, 1990

11 WHO Study Group. Diet, nutrition, and the prevention of chronic diseases. WHO Tech Rep Ser 1990;797.

12 World Health Organisation Regional Office for Europe. Targets for health for all. Copenhagen: WHO, 1985.

13 United States Department of Health and Human Services. Promoting health/ preventing disease: objectives for the nation. Washington, DC: United States Government Printing Office, 1980 .

14 Steering Comminee (chairman Rose G. Coronary heart disease plans for action. A report based on an interdisciplinary workshop conference held at Camterbury. A report based on an interdisciplinary workshop
28-30 September 1983. London: Pitman, 1984.

15 National Forum for Coronary: Heart Disease Prevention. Action in the UK 1984-1987. London: Health Education Authority, 1988.

16 National Audit Office. Report by the Comptroller and Auditor General. National Health Service: coronary heart disease. London: HMSO, 1989. (House of Commons Paper 208.)

17 House of Commons Committee on Public Accounts. Coronary heart disease. 26ith Report, session 1988-89. London: HMSO, 1989.

\title{
Importance of obesity
}

\section{John Garrow}

Circulatory disease, cancers, and respiratory disease account for $21 \%, 26 \%$ and $5 \%$ respectively of years of life lost up to the age of 65 and $13 \%, 7 \%$, and $6 \%$ respectively of NHS expenditure.' These are the three biggest causes of mortality and morbidity. Obesity contributes to deaths from all three of these causes and is also associated with other diseases (figure), which makes it a prime candidate for being recognised as a key area.

For two decades it has been the received wisdom among epidemiologists that obesity is not an independent risk factor for cardiovascular disease. The seven nations study showed that if you know the age, blood pressure, smoking habits, and serum cholesterol concentration of men aged 40-60 then knowing their adiposity does not help to make any better prediction about which men will have a heart attack in the next five years. ${ }^{2}$ Even if this premise is correct (and other investigators have reached different conclusions from analysis of the same data ${ }^{3}$ it does not follow that obesity is benign -it has been called the most readily identifiable of all risk factors. ${ }^{+}$

\section{How obesity causes disease}

Recent work on obesity in animal models has shown that the primary metabolic defect is a reduced sensitivity to insulin, from which all the other metabolic characteristics associated with obesity follow. ${ }^{5}$ The classic study by Sims et al showed that if experimental obesity is produced by prolonged overfeeding of normal men with no family history of diabetes a similar syndrome of insulin insensitivity is produced, which reverts to normal with weight loss. ${ }^{6}$ Susceptibil- 
ity to arterial disease increases in parallel with increasing glucose intolerance, ${ }^{+}$so this is one route by which obesity predisposes to cardiovascular disease. Glucose intolerance, or serum insulin concentration, is also highly correlated with hypertension.? In addition, regardless of insulin insensitivity, obesity is associated with an unfavourable plasma lipoprotein pattern, with high low density lipoprotein cholesterol and triglyceride concentrations and low high density lipoprotein cholesterol concentration,${ }^{+8}$ which is also linked with cardiovascular disease.

Another route by which obesity causes disease arises because adipose tissue contains the enzyme system

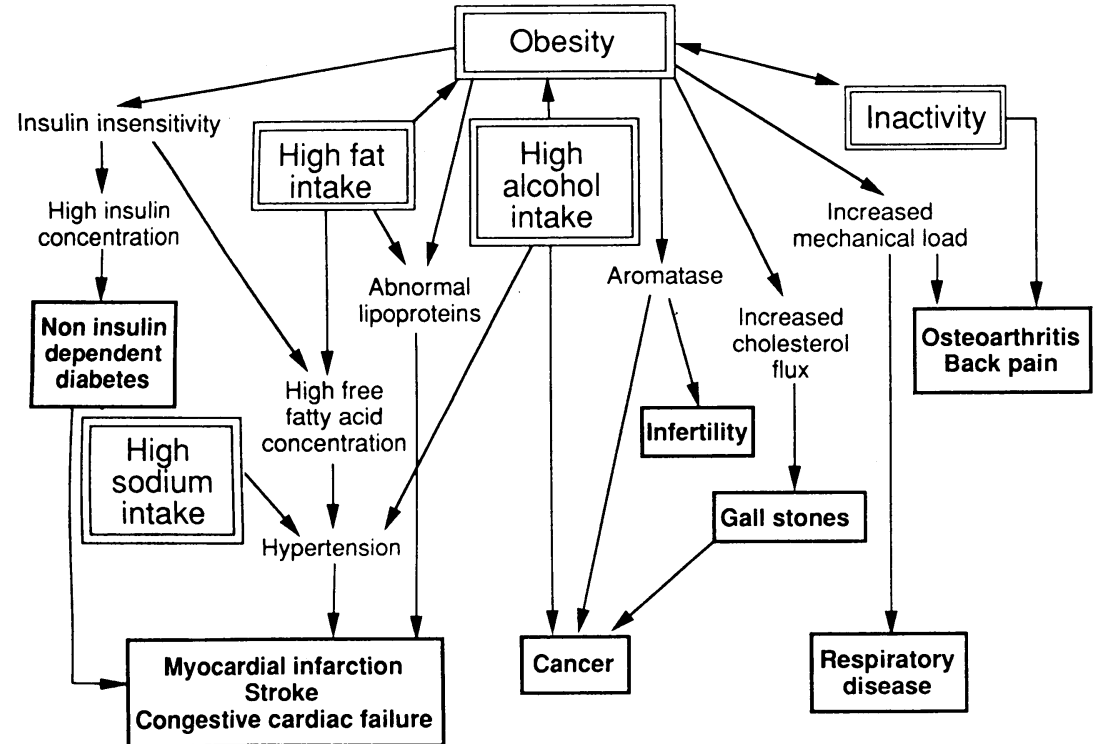

Effect of obesity and activities leading to obesity on important causes of death and illness aromatase, which converts androgens to oestrogens." The resulting hormonal imbalance contributes to infertility and the polycystic ovary syndrome, which are common complications of obesity. The imbalance also probably explains the increased prevalence of sex hormone sensitive cancers in obese people. ${ }^{10}$ Adipose tissue is also an important reservoir of cholesterol, so obese people have a greatly increased cholesterol flux and supersaturated bile, " which makes them prone to gall stones, abnormal liver function, ${ }^{12}$ and gall bladder cancer. ${ }^{10}$

Finally, the increased mechanical load associated with obesity contributes to the reduced exercise tolerance and respiratory problems of obese people and the increased risk of musculoskeletal diseases and osteoarthritis in weight bearing joints. ${ }^{913}$

\section{Does weight loss reverse the health risk of obesity?}

Indirect evidence strongly suggests that weight loss does reverse almost all the health hazards of obesity. Life insurance data show that people who were impaired solely on account of obesity have normal insurance risks after losing weight. ${ }^{14}$ The reversibility of insulin insensitivity has already been mentioned, and all the risk factors for coronary heart diseaseblood pressure; cholesterol, triglyceride, uric acid, and fasting glucose concentrations; forced vital capacity -also improve with weight loss. ${ }^{15}{ }^{16}$ The obese patient who loses weight is likely to improve greatly with respect to infertility ${ }^{17}$ and osteoarthritis of the knees. ${ }^{18}$ There is no information about the effect of weight loss on the risk of sex hormone sensitive cancers or on the social discrimination that obese people often suffer, ${ }^{19}$ but from our knowledge of the aetiology it is reasonable to expect that these would also improve.

The only disadvantage of losing weight seems to be that while it is being lost the mobilisation of cholesterol in adipose tissue makes the bile even more saturated.

\section{Government's view on obesity}

Obesity is increasing in both men and women. In $1986-7,12 \%$ of women and $8 \%$ of men were obese compared with $8 \%$ and $6 \%$ respectively in 1980 . In addition, $37 \%$ of men and $24 \%$ of women were overweight in 1986-7.

High blood cholesterol concentrations and raised blood pressure are linked with obesity. Both these conditions could be addressed by a reduction in obesity.

Target: By the year 2000 the proportion of obese adults should be $7 \%$ or less.

\section{Case against obesity as key area}

I have already considered and dismissed the fallacious argument that obesity by itself is not a risk factor. More serious objections are that obesity cannot be effectively treated, that campaigns against obesity will increase the prevalence of anorexia nervosa, and that obesity confers some protection against hip fracture in old people.

The effective treatment of obesity requires patience and an understanding of the principles of energy balance, ${ }^{21}$ qualities which some doctors are unable or unwilling to deploy, so they declare obesity to be untreatable. ${ }^{.1}$ However, there is no metabolic barrier to achieving any desired weight loss with a conventional energy reducing $\operatorname{diet}^{9} "$; ; the effectiveness of treatment depends mainly on the conviction of patient and therapist that weight loss is possible and worth the effort.

People who campaign against obesity need to be aware that any advice about how to lose weight will be avidly taken up by young women of normal weight who want to be unphysiologically thin. It is therefore necessary to specify clearly the range of weight for height for which the advice is given and to avoid concepts such as "an ideal weight"; instead, a range of desirable weights should be specified. There is no evidence that propaganda against obesity thus worded increases the prevalence of anorexia nervosa. Also such advice should be aimed chiefly at overweight young people (see below); old people benefit less and are disadvantaged more by weight loss.

\section{Targets for preventing obesity}

The target proposed by the Department of Health for obesity contains one prevalence for adults of all ages (box). The excess mortality associated with obesity is highest among people under 50 years old; those who will be 50 in 2005 are 36 years old now. I propose that the targets should be different for different age groups. The table shows the prevalence of obesity in the United Kingdom in 1980 and 1987 and my suggested targets for the year 2005 .

\section{Strategy to achieve targets}

I believe that three components are needed for effective prevention of obesity in Britain. Firstly, the public must be informed about the range of weight for

Prevalence (\%) of obesity (Quetelet's index $>30 \mathrm{~kg} / \mathrm{m}^{\prime}$ ) in a representative sample of men and women aged 16-64 in the United Kingdom in 1980 and $1987^{\circ i}$ and target prevalences for the year 2005

\begin{tabular}{lrrrrrrr}
\hline & \multicolumn{3}{c}{ Men } & & \multicolumn{3}{c}{ Women } \\
\cline { 2 - 5 } \cline { 6 - 8 } Age (years) & 1980 & 1987 & 2005 & & 1980 & 1987 & 2005 \\
\hline $16-24$ & $2 \cdot 5$ & $3 \cdot 0$ & $2 \cdot 0$ & & $3 \cdot 5$ & $6 \cdot 0$ & $2 \cdot 0$ \\
$25-34$ & $4 \cdot 5$ & $6 \cdot 0$ & $4 \cdot 0$ & & $4 \cdot 5$ & $11 \cdot 0$ & $4 \cdot 0$ \\
$35-49$ & $8 \cdot 0$ & $11 \cdot 0$ & $6 \cdot 0$ & & $9 \cdot 9$ & $10 \cdot 0$ & $6 \cdot 0$ \\
$50-64$ & $7 \cdot 7$ & $9 \cdot 0$ & & & $14 \cdot 3$ & $18 \cdot 0$ & \\
\hline
\end{tabular}


height that is associated with appreciable health risks in order to warn those who should be taking some action and to reassure those who should not. This is already being undertaken by the Health Education Authority, ${ }^{2+}$ but it is a task in which all health carers should share.

Secondly, there must be affordable slimming groups open to members of the public who want sound advice about dieting. The information should go beyond the narrow objective of weight loss and should incorporate advice on intake of fats, alcohol, salt, and fibre ${ }^{25}$ and on exercise. ${ }^{20}$ Such a scheme has been running in the Harrow Health District for 14 years. ${ }^{27}$ The members are mainly married women, who are well placed to pass on this information to their families. It greatly strengthens the authority of leaders of such groups if a specialist hospital clinic provides back up to cope with members who are "difficult" to help for metabolic or personality reasons.

Thirdly, there should be a policy in primary schools to identify children starting school who are above the 90th centile of weight for height and to provide facilities so these children increase normally in height between the ages of 7 and 12 years but slightly less than normally in weight. An average child gains about $22 \mathrm{~kg}$ over these five years, and a 7 year old who is $4 \mathrm{~kg}$ overweight for height is appreciably overweight. If that child gains $18 \mathrm{~kg}$ by the age of 12 , he or she should then be normal weight for height.

\section{Problems of implementing this strategy}

There should be no great difficulty about implementing the first two components of the strategy; pilot schemes have been running well. But there has never been an organised attempt to prevent obesity in our schools, and this requires the intelligent cooperation of parents, school teachers, community dietitians, school nurses, and caterers. Unfortunately, giving overweight children fruit instead of sweets and low energy drinks instead of sugary colas may be seen as a punishment instead of an advantage. As always, education is the key, and rapid results are not to be expected.

This strategy also needs the backing of those in primary health care, who could easily sabotage the scheme by hostility or even indifference. We lack any systematic information about what general practitioners do for their obese patients and with what effect, and we do not know what proportion of practices regard obesity as a cosmetic problem for which the remedies are available from commercial slimming clinics. Research into this is urgently needed.

1 Secretary of State for Health. The health of the nation. London, HMSO, 1991 (Cm 1523.

2 Keys A, Aravanis C, Blackburn H, van Buchem FSP, Buzina R, Djordjeuik BS, et al. Coronary heart disease: overweight and obesity as risk factors Ann Intern Med 1972:117:15-27.

3 Hubert $\mathrm{H}$. The importance of obesity in the development of coronary risk factors and disease: the epidemiological evidence. Annu Rev Public Health 1986;7:493-502.

+ Shaper AG. Coronary heart disease, risks and reasons. London: Current Medical Literature, 1988 .

5 Jeanrenaud B. Neuroendocrinology and evolutionary aspects of experimental obesity. In: Oomura Y, Tarui S, Inoue S, Shimazu T, eds. Progress in obesity research 1990. London: John Libbey, 1991:409-2

6 Sims EAH, Danforth EJr, Horton ES, Bray GA, Glennon JA, Salans LB. Endocrine and metabolic effects of experimental obesity in man. Recent Prog Horm Res 1973;29:457-96.

7 Modan M, Halkin H, Almog S, Lusky A, Eshkol A, Shefi M, et al. Hyperinsulinaemia: a link between hypertension obesity and glucose intolerance. F Clin Invest 1985;75:809-17.

8 Forde $\mathrm{OH}$, Thelle DS, Arnesen E, Mjos OD. Distribution of high density lipoprotein cholesterol according to relative body weight, cigarette smoking and leisure time physical activity. Acta Med Scand 1986;219:167-71.

9 Garrow JS. Obesity and related diseases. London: Churchill Livingstone, 1988.

10 Garfinkel L. Overweight and cancer. Ann Intern Med 1985;103:1034-6.

11 Reuben A, Maton PN, Murnhy GM. Dowling RH. Bile lipid secretion in and non-obese individuals with and without gall stones. Clin $S c i$ in ob5;69: $71-9$.

12 Nomura F, Ohnishi K, Satomura Y, Ohtsuki T, Fukungaga $K$, Honda $M$, et al. Liver function in moderate obesity - study in 534 moderately obese subjects among 4613 male company employees. Int $f$ Obes 1986;10:349-54.

13 Rissanen A, Heliovaara M, Knekt P, Reunanen A, Aromaa A, Maatela J. Risk of disability and mortality due to overweight in a Finnish population. $B M \mathcal{F}$ 1990:301:835-6.

14 Dublin LI. Relation of obesity to longevity. N Engl F Med 1853;248:971-4

15 Borkan GA, Sparrow D, Wisniewski C, Vokonas PS. Body weight and coronary heart disease risk: patterns of risk factor change associated with long-term weight change. $A m \mathcal{F}$ Epidemiol 1986;124:410-9.

16 Hubert HB, Feinleib M, McNamara PM, Castelli WP. Obesity as an independent risk factor for cardiovascular disease: a 26-year follow-up of participants in the Framingham heart study. Circulation 1983;67:968-77.

17 Friedman CI, Kim MH. Obesity and its effect on reproductive function. Clin Obstet Gynecol 1985;28:645-63.

18 Dixon AS, Henderson D. Prescribing for osteoarthritis. Prescribers' Journal 1973;13:41-9.

19 Sonne-Holm S, Sorensen TI. Prospective study of attainment of social class of severely obese subjects in relation to parents' social class, intelligence and education. $B M \mathcal{J}$ 1986;292:586-9.

20 Garrow JS. Treating obesity. $B M \mathcal{J}$ 1991;302:803-4.

21 Hall A, Stewart D. Obesity: time for sanity and humanity. $N Z$ Med $\mathcal{J}$ 1989;102:134-6.

22 Bortz WM. A 500 pound weight loss. Am f Med 1969;47:325-31.

23 Gregory J, Foster $\mathrm{K}$, Tyler $\mathrm{H}$, Wiseman $\mathrm{M}$. The dietary and nutritional survey of adults. London, HMSO, 1990.

24 Garrow JS. Overweight and obesity: a briefing paper. London: Health Education Authority (in press)

25 Bingham S. Dietary aspects of a health strategy for England. BM 1991;303: 353-5.

26 Pentecost BL. Medical aspects of exercise. London, Roval College of Physicians of London, 1991.

27 Bush A, Webster J, Chalmers G, Pearson M, Penfold P, Brereton P, et al. The Harrow Slimming Club: report on 1090 enrolments in 50 courses, 1977 1986. Fournal of Human Nutrition and Dietetics 1988;1:429-36.

\section{ANY QUESTIONS}

For how long should pressure be applied over the site of venepuncture and for how long should the arm be rested in someone who is returning immediately to active physical work?

Surprisingly little is written on this question. The usual recommendation is to "apply pressure until bleeding has stopped." True, but not very helpful. Several factors need to be considered: ease of venepuncture; site (antecubital fossa, back of hand); age of patient; scarring from many previous venepunctures; and, finally, size of needle used for venepuncture - that is, standard 20 to 23 gauge needle for diagnostic sampling or that used for blood donation. In addition, is the patient known to have thrombocytopenia or a coagulation disorder, either hereditary or due to anticoagulant treatment?

I am not aware of any standard times, but the usual practice is to have the patient press on a cotton wool ball, with the arm outstretched, while the phlebotomist is filling, mixing, and labelling the containers. This takes about one minute. The elbow should not be bent. The site should be inspected after removal of the cotton wool ball; it should not be rubbed as this is likely to dislodge the clot.
A plaster serves no purpose other than to prevent soiling of the shirt sleeve. There will be the inevitable occasion when patients return to the blood test room with blood running down their arm; at our hospital the procedure outlined above reduces this risk to a minimum.

An immediate return to active physical work is expected after a diagnostic venepuncture. For those donating blood, when a large bore needle is used and blood volume is considerably reduced, a rest period of 15 to 20 minutes is encouraged. A frequently punctured vein with scarring of the skin will not stop bleeding so readily. I hold my arm aloft, maintaining pressure for two minutes. The site is covered with a plaster and a pressure dressing. This may be helpful for a patient who returns with bleeding from the site of venepuncture, and this local pressure dressing may benefit patients with thrombocytopenic oozing.

Venepuncture of veins on the back of the hand needs longer pressure. There is little supporting tissue, especially in the elderly, whose veins are fragile, and a pressure dressing should be applied, much as is done by anaesthetists when using these veins for induction of anaesthesia. $-E \mathrm{~J}$ PARKER-WILLIAMS, consultant haematologist, London 